\title{
Simulator training in gastrointestinal endoscopy - From basic training to advanced endoscopic procedures
}

S.E. van der Wiel, MD, Research Fellow ${ }^{\mathrm{a}, 1}$,
R. Küttner Magalhães, MD, Gastroenterologist, Staff Member ${ }^{\text {b, } 2 \text {, }}$

Carla Rolanda Rocha Gonçalves, MD, PhD, Gastroenterologist, Staff Member e, f, g, 4 ,

M. Dinis-Ribeiro, MD, PhD, Gastroenterologist, Professor, Head of Department ${ }^{\text {c, d, } 3 \text {, }}$ M.J. Bruno, MD, PhD, Gastroenterologist, Professor, Head of Department ${ }^{\text {a, }}$, A.D. Koch, MD, PhD, Gastroenterologist, Staff Member ${ }^{\text {a, * }}$

a Department of Gastroenterology and Hepatology, Erasmus MC - University Medical Center Rotterdam, 's Gravendijkwal 230, 3015 CE Rotterdam, The Netherlands

${ }^{\mathrm{b}}$ Department of Gastroenterology, Santo António Hospital, Porto Hospital Center, Largo Prof. Abel Salazar, 4099-001 Porto, Portugal

${ }^{\mathrm{c}}$ Department of Gastroenterology, Portugese Oncology Institute of Porto, Rua Dr. Bernardino de Almeida, 4200-072 Porto, Portugal

d CIDES/CINTESIS, Porto Faculty of Medicine, Portugal

${ }^{\mathrm{e}}$ Life and Health Sciences Research Institute, School of Health Sciences, University of Minho, Braga, Portugal

${ }^{\mathrm{f}}$ Life and Health Sciences Research Institute/3B's - PT Government Associate Laboratory, Braga/Guimarães, Portugal

g Department of Gastroenterology, Hospital Braga, Portugal

Abbreviations: OGD, oesophagogastroduodenoscopy; EMR, endoscopic mucosal resection; EMS, ERCP mechanical simulator; ESD, endoscopic submucosal dissection; ERCP, endoscopic retrograde cholangiopancreatography; EUS, endoscopic ultrasound; GI, gastrointestinal; $V R$, virtual reality.

* Corresponding author. Tel.: +31 107040045; fax: +31 107030352.

E-mail addresses: s.e.vanderwiel@erasmusmc.nl (S.E.van der Wiel), rkuttner@gmail.com (R. Küttner Magalhães), crolanda@ ecsaude.uminho.pt (C.R. Rocha Gonçalves), mdinisribeiro@gmail.com (M. Dinis-Ribeiro), m.bruno@erasmusmc.nl (M.J. Bruno), a.d.koch@erasmusmc.nl (A.D. Koch).

1 Tel.: +31 107033040; fax: +31 107030352 .

2 Tel.: +351 22207 7500; fax: +351223320318.

3 fax: +351225084055 .

4 Tel.: +351253604912.

5 Tel.: +31 107035946; fax: +31 107030352 . 


\section{Keywords:}

Endoscopy

Gastrointestinal

Endoscopic procedures

Simulation training

Computer simulation

\section{A B S T R A C T}

\begin{abstract}
Simulator-based gastrointestinal endoscopy training has gained acceptance over the last decades and has been extensively studied. Several types of simulators have been validated and it has been demonstrated that the use of simulators in the early training setting accelerates the learning curve in acquiring basic skills. Current GI endoscopy simulators lack the degree of realism that would be necessary to provide training to achieve full competency or to be applicable in certification. Virtual Reality and mechanical simulators are commonly used in basic flexible endoscopy training, whereas ex vivo and in vivo models are used in training the most advanced endoscopic procedures. Validated models for the training of more routine therapeutic interventions like polypectomy, EMR, stenting and haemostasis are lacking or scarce and developments in these areas should be encouraged.
\end{abstract}

(C) 2016 Elsevier Ltd. All rights reserved.

\section{Introduction}

During the last decades simulation-based training has gained more acceptance in teaching basic endoscopy skills to novice endoscopists. Traditionally, trainees learn to perform endoscopy by handson training in a clinical setting under the supervision of a trained endoscopist, the so-called master apprentice model. The main benefit of this teaching method is on-the-job training under one-on-one supervision by an experienced endoscopist offering immediate feedback. However, taking the first steps in flexible endoscopy while performing procedures on actual patients has certain drawbacks. It is learning by 'trial and error', which potentially increases patient discomfort and risk of complications. It also adds extra time to each procedure affecting capacity and economics [1]. An important drawback of such an approach is that with this type of training it is difficult for novices to appropriately process feedback in a stressful situation with an overload of new information. The approach of 'see one, do one and teach one' therefore seems outdated and no longer appropriate in the modern education of medical professionals, in particular in their early learning curve. Skillslabs and simulators offer the potential to train in a dedicated 'learning environment'. This is a safe environment for trainees where no possible harm can be done to patients. Stress factors related to doing a procedure in a live patient are eliminated to create an optimal setting for training. In this particular learning environment, it is also entirely possible to combine hands-on training with thorough theoretical teaching. Exercises can be repeated multiple times in small building blocks or specific scenario's until fully mastered.

In recent years, a number of studies have been published on simulator training, usually describing the benefit of simulator training in the early learning curve towards competency. A recent systematic review demonstrated moderate quality evidence for simulator-based training in forward viewing flexible endoscopy and ERCP. The review reveals that the use of virtual reality simulators in the early training setting accelerates the learning of practical skills [2]. However, the literature on simulator training for more advanced therapeutic procedures is scarcer, aside from studies on managing acute gastrointestinal bleeds or advanced endoscopic resection in ex vivo or in vivo animal models. A realistic simulation model for polypectomy, one of the most frequently performed therapeutic procedures, is still lacking among currently available simulators. Compared to the aviation or automotive industry, we can only acknowledge with envy that we are miles behind when it comes to realistic medical simulators.

In this chapter we will outline the well-established role of simulators in basic endoscopy training and elaborate on the role of (virtual reality (VR)) simulators, mechanical models, ex vivo and in vivo models for training in advanced endoscopic procedures. 


\section{Available simulators}

The first simulators for flexible endoscopy were developed in the 1960s. In general there are four types of simulators: 1) mechanical simulators, 2) live animal models, 3) ex vivo models and 4) VR computer simulators. The first endoscopic simulators were mechanical models, designed especially for training sigmoidoscopy and colonoscopy. Live animal models seem to be the most realistic compared to mechanical models with haptic feedback resembling that of human tissue, although there are distinct differences in wall thickness and orientation of various organs, resulting in a slightly different 'feel'. Live animal models have certain drawbacks including the costs involved, the fact that they can only be used in specially equipped facilities, that they cannot be used indefinitely, and that many ethical concerns have been raised by the public [4]. A good alternative for live animal models is ex vivo models, composite and explanted animal organ simulators. These models consist of a combination of plastic parts and explanted animal organs obtained from slaughterhouses. They overcome some of the aforementioned limitations of the live animal models and have proven useful in specific training scenarios. Currently VR simulators are the most promising tools. They are available plug-and-play, making it accessible for trainees to train at their own pace and procedures can be repeated as many times as desired.

The optimal training model or simulator has to show the highest degree of content validity as well as concurrent validity. This means that the system has a high level of resemblance to the real life activity and that performance on the model should be readily transferrable to the real life activity, in casu patient-based endoscopy. Lesser, but more commonly used forms of validity are expert and construct validity. These terms describe the degree of realism as judged by experts and the ability of the simulator to distinguish different levels of competence [3]. The reliability of a simulator relates to its ability to provide consistent results with minimal errors of measurement. The most commonly used test is the test-retest reproducibility. It predicts to what extent a subject can 'beat the test' by repeated assessment [5].

\section{Role of simulators in basic forward viewing flexible endoscopy training}

Advanced therapeutic endoscopy has proven itself as an effective and safe first-line treatment for the management of early gastrointestinal neoplasia, pancreatico-biliary disease and many more conditions. Conditions formerly restricted to the domain of surgeons are now managed using minimally invasive endoscopic techniques, not only with considerably less morbidity and mortality, but also superior postprocedural functional results. Moreover, diagnostic endoscopic procedures are gaining importance largely as a result of the initiation of colorectal cancer screening programs in many countries worldwide. As a consequence, the increasing number and in particular the higher complexity of endoscopic procedures demands more skilled endoscopists able to perform these procedures in a competent manner. Simulation-based learning programs have proven to be of added value, they can effectively speed up the learning process in the early stages of training, avoid patient harm and lower one-on-one instructor time. Consequently, the use of simulators in the early training phase in different gastrointestinal procedures is gaining acceptance and several simulators have been validated for this purpose $[2,6]$.

\section{Oesophagogastroduodenoscopy}

Oesophagogastroduodenoscopy (upper gastrointestinal endoscopy, OGD) is widely used for the diagnosis and treatment of oesophageal, gastric and small bowel conditions. In general, it is a safe and well-tolerated procedure. A variety of technical and cognitive aspects must be mastered in order to perform a high-quality examination. Although OGD is a common gastrointestinal (GI) procedure, studies concerning simulator-based training are scarce compared to colonoscopy. A possible explanation might be the fact that by gaining competency to perform a colonoscopy, where the need for endoscope handling and manoeuvring is much higher, performing OGD seems relatively easy. Several simulators have been developed for training OGD: mechanical models, in vivo and ex vivo animal models and VR simulators. The only validated VR-simulator for training upper endoscopy is the 'GI Mentor' virtual reality computer simulator (Fig. 1) [7,8]. 


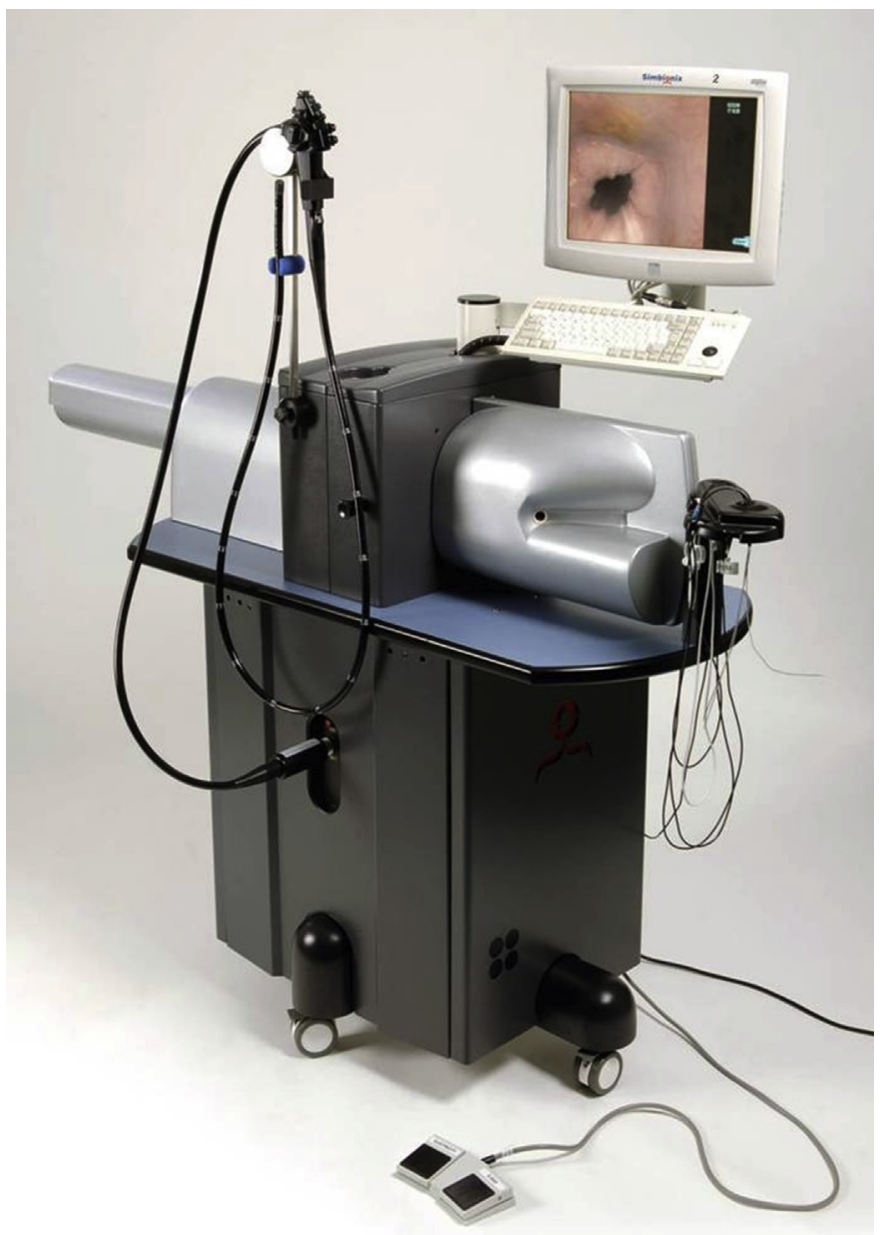

Fig. 1. The Simbionix GI Mentor II.

Not much is known about the validation and use of mechanical models for basic training in upper GI endoscopy. Most models appear inappropriate for training as the level of competency gained by the trainee has been negligible [9]. The best known ex vivo model is the Erlangen Endo-Trainer [10]. The model is mostly appreciated for training bleeding situations and seems to offer a good training scenario. Validation studies or studies on learning curves are however few. These include three studies that used the 'GI Mentor' VR simulator, to evaluate the learning curve in simulator-based OGD training [11-13]. The main outcome measures in these studies were procedure time and time to reach specific landmarks such as passing the oesophagus and the pylorus and intubating the duodenum. Secondary outcomes were intubation time, movement techniques, procedural success rates and patient outcome such as pain and discomfort. All these studies have shown that simulator-trained participants, compared to controls, have a significantly lower overall procedure time and a significantly improved technical accuracy. The simulator-trained group also appears to operate more independently compared to the controls. The training with these simulators was of no benefit to experienced endoscopists [7,11-14].

The model has an added value in training novice endoscopists, but the effect of training overall seems to be limited. One study showed that the effect of simulation-based training was still visible after the first 60 endoscopic procedures as measured by a shorter procedure time, but not with regards to 
neither the technical and diagnostic accuracy nor the patients' comfort levels [12]. Another important finding was that performance scores derived from the simulator, did not correlate with performance scores given by blinded experts $[15,16]$. These findings suggest that the virtual reality simulator training in OGD offers limited added value to patient-based training and only in the very early learning period $[12,14,17-19]$.

\section{Colonoscopy}

The use of simulators in colonoscopy training has been extensively studied and remains a topic of ongoing research. Multiple studies have been performed in which mechanical, ex vivo and VR simulators have been validated for training colonoscopy [2]. The Kyoto Kagaku Colonoscope Training model is currently the only mechanical model that has been validated. Performance on this model has been shown to correlate well with the level of expertise of endoscopists as measured by caecal intubation in patient-based endoscopy [20]. A validation study using an ex vivo bovine colon model demonstrated good construct, expert and concurrent validity. A strong correlation was seen between performance on the model and outcome during patient-based colonoscopy, suggesting the potential of an effective tool for assessment of competency [21]. The most convincing evidence currently available in training

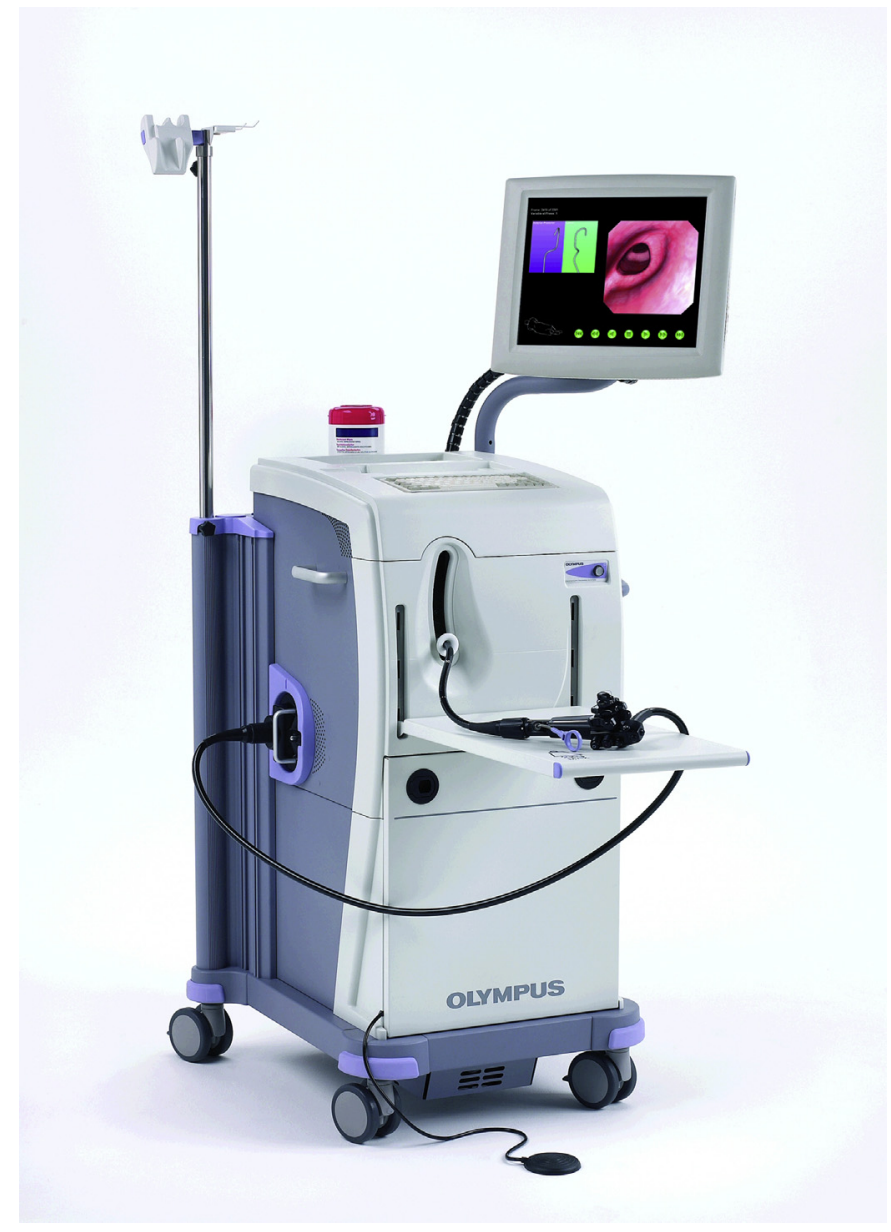

Fig. 2. The Olympus Endo TS-1 VR simulator. 
colonoscopy is on VR simulators. Multiple validation studies have been performed, evaluating three different VR simulators; The Simbionix GI Mentor II (Fig. 1), the Olympus Endo TS-1 VR Simulator (Fig. 2) and the CAE Endo VR Simulator, formerly known as the AccuTouch Immersion Medical Computer Simulator $[2,7,14,16,17,21-32]$. All of these simulators appear to be valid for basic colonoscopy training. Training on VR colonoscopy simulators focusses mainly on intubation skills. There are hardly any data available on training withdrawal skills and mucosal inspection or therapeutic procedures like polypectomy. Most studies had a randomized design, comparing simulator-based training versus no training followed by routine patient-based training or comparing simulator-based training versus patient-based training followed by patient-based assessment [33-42]. It has been demonstrated that simulator training leads to improved performance compared to no training lasting up to the first 80 colonoscopies in humans and that simulator training compared to patient-based training results in equal performance in the early phase of learning. A recent study using the GI Mentor demonstrated increased performance during patient-based colonoscopy after prolonged training on the simulator. After an average of 60 simulator procedures the learning effect on the simulator itself ceased which coincided with observations in patient-based colonoscopy. This tells us that when the learning effect on the simulator stops, the same applies for the transfer to patient-based endoscopy and the time has come to continue training in a human setting. The simulator derived learning effect can probably be extended when the degree of realism of the simulator increases. This observation is a well-known concept in high fidelity aviation simulators [43]. Based on currently available evidence, the effectiveness of simulator-based training in speeding up the early learning curve, thereby reducing patient's burden has been well established. The use of simulators in colonoscopy is therefore strongly recommended prior to performing patient-based endoscopy. To get the most out of simulator training it seems to make sense to train up to the point where the learning effect on the simulator itself levels off. This provides the opportunity to offer tailored training programs to novice endoscopists and determine when to commence patient-based endoscopy on an individual basis.

\section{Role of simulators in advanced endoscopy training}

\section{Endoscopic retrograde cholangiopancreatography}

Endoscopic Retrograde Cholangiopancreatography (ERCP) is considered an advanced endoscopic procedure and, in most countries, is not part of the routine training of novice endoscopists. It is one of the most technically demanding and high-risk procedures in GI endoscopy. Serious life-threatening short-term and long-term complications may arise as a result of an ERCP procedure, including postERCP pancreatitis, bleeding and perforation. It requires a great deal of training and an extensive number of procedures to achieve competency. Nowadays diagnostic ERCP procedures are considered obsolete, meaning that all ERCP procedures are performed with a therapeutic intent. In order to minimize patient risk, trainees need to be properly trained both clinically as well as technically and exposed to high numbers of procedures under the guidance of experts before reaching a status of competency. Simulator-based training seems ideally suited as a training platform for this complex procedure before embarking on real life procedures. Surprisingly, there is very limited data available concerning endoscopic simulators in ERCP training. A total of 6 simulators have been described, including mechanical simulators, a model utilizing ex vivo porcine organs, the anesthetized pig model and computer models. Known mechanical simulators with a module for ERCP training include the XVision ERCP Training system and the ERCP Mechanical Simulator (EMS) [44,45]. These models are made out of aluminium, plastic and rubber components, with either a synthetic or ex vivo papilla and provide the possibility to train with real endoscopes and accessories. Selective bile duct or pancreatic duct cannulation can be practised with selective stent placement, balloon dilatation, brush cytology and, in some, sphincterotomy. Practising stone extraction has not been described in any of the models. Primary outcome parameters in studies evaluating the mechanical model are successful selective cannulation of the biliary duct and the time required to complete several procedures. Both models are able to distinguish between novice endoscopists and experienced endoscopists by means of expert assessment. After a short mechanical simulator training course a higher number of successful cannulation rates was seen in simulator-trained participants in patient-based ERCPs [45-48]. This 
improved performance was only described for the first 25 consecutive procedures in humans as followup time was limited. Live anesthetized porcine models also have been used as a model for ERCP training. This model has been shown to be adaptable to all procedural aspects of ERCP including cannulation, stent placement and sphincterotomy. After a two-day hands-on training course participants showed an increase in confidence scores, especially in performing more complex procedures like needle-knife pre-cut sphincterotomy [49,50]. Puzzlingly, confidence in performing basic skills did not increase. The Erlangen Endo Trainer can also be equipped with an ERCP module, consisting of an ex vivo porcine stomach model with attached biliary system. It allows trainees to train with a real endoscope and accessories. The model has been extensively used in ERCP training workshops [51,52]. The Erlangen Endo Trainer, as well as the live animal model, scored high on realism and the model seems most useful in teaching basic ERCP skills [10,52]. The only validated VR endoscopy simulator in ERCP is the Simbionix GI Mentor II VR Simulator. The model is able to differentiate between novices and experts in time to complete procedures and time to reach the papilla; however the model received a low score for realism [53]. Recently, a study was performed using the CAE Endo VR Simulator. This simulator provides a platform for training in diagnostic procedures, however it seems not to be useful in measuring change in performance over time and assessing competency [54]. Sedlack et al. performed a comparison validation study including the Erlangen Endo Trainer, the live porcine model and the GI Mentor II. The study concluded that each model has the potential to be included in training programs; however the Erlangen Endo Trainer scored highest on indices of realism, usefulness and performance. The GI Mentor II scored significant lower at indices of realisms but is easier to incorporate in a training program [52]. The most common performance parameter in simulator-based training in ERCP is successful cannulation rate. This measure reflects only part of the complexity and diversity of this therapeutic procedure. A successful biliary cannulation is a prerequisite to complete a therapeutic procedure successfully but is not a good predictor for successful ERCP procedure. All of these simulators show definite training potential, but based on the scant scientific data available, a definite recommendation for a well-described training program cannot be provided.

\section{Endoscopic ultrasound}

Since the description of the first transgastric pancreatic pseudocyst drainage using a linear echo endoscope by Grimm et al., endosonography (EUS) has rapidly changed from a mere diagnostic tool to a technique with advanced therapeutic capabilities [55]. Notably, the advanced EUS therapeutic procedures have a marked overlap with ERCP and demand a great deal of expertise and experience. Although the need for highly skilled endoscopists is obvious, validated simulators or models for training are lacking. There are only a few reports on simulator-based training in EUS. A learning effect by repeated exercise and improvement of performance during EUS procedures in the live porcine model was demonstrated by Barthet et al. but no formal attempts at validation or transfer of competence to a patient-based setting have been made [56]. Advanced endoscopic resections such as endoscopic mucosal resection (EMR) and endoscopic submucosal dissection (ESD) are typically trained in a simulator-based setting using animal models. Both ex vivo and in vivo models are used. The ex vivo model is mostly used for training bleeding complications. These topics are discussed in a separate paragraph below.

\section{Advanced therapeutic procedures}

Simulator-based training has demonstrated its use in training the basic skills in GI endoscopy. However, as GI endoscopy is no longer a merely diagnostic procedure, this obviates the need for training an increasing diversity of advanced therapeutic procedures outside the standard clinical scenario. Unfortunately we must acknowledge that there is very limited evidence to support training of these procedures in a skillslab environment. Standard polypectomy or endoscopic mucosal resection (EMR) are perfect examples of techniques that currently cannot be trained in any of the models or VR simulators with a degree of resemblance that comes close to the real thing. A few studies using the Erlangen Endo Trainer have demonstrated a positive effect of simulator-based training for certain interventional skills like endoscopic haemostasis and perforation closure. Haemostasis was simulated 
using several techniques and a significant improvement has been documented in performing successful injection or coagulation therapy $[4,10,57]$. The transfer of these skills to patient-based endoscopy and its impact in real-life practice is usually not described, so from a scientific point of view we cannot conclude that training in these models is useful. However, as these training scenarios closely resemble the clinical setting, using the same instruments, it seems common sense that training in these models will at least partially improve the skills necessary to apply these techniques.

\section{Advanced endoscopic resections}

Pre-malignant and early neoplastic lesions are commonly detected in clinical practice. Interventional endoscopy, namely endoscopic submucosal dissection (ESD) and complex endoscopic mucosal resection (EMR) have replaced surgery for the treatment of many of these conditions. EMR of large lesions can be technically demanding and allows for en bloc resection of lesions up to $20-25 \mathrm{~mm}$. Lesions larger than this typically require piecemeal EMR which can complicate histological staging in some settings and can be considered a limitation regarding early cancers, depending on the location in the GI tract [58]. In these situations, ESD seems to be the resection technique of choice, but it is technically more challenging and has a more prolonged learning curve [59-62]. In the appropriate setting, ESD is comparable to surgery in terms of oncological outcomes, cancer free survival and recurrence, but with considerably lower costs, operative time, hospital stay, complication rates and mortality [63]. ESD had a widespread dissemination in Eastern countries but a relatively slow diffusion in Western countries due to its complexity, the requirement for considerable endoscopic skills, the high potential of serious adverse events and the difficulty in achieving adequate funding for these complex endoscopic procedures. A learning curve in performing successful ESD procedures has been demonstrated, and more experienced endoscopists have higher rate of en bloc resection, reduced procedure duration and fewer adverse events, mostly related to perforations [64,65]. Therefore, a pre-patient training program is recommended before ESD is performed in the clinical setting $[64,66,67]$. The differences between the East and West support the use of simulators for ESD training in the West, whereas in the East, where expert supervision and suitable learning cases are easily available, a simulator phase may not be necessary [68]. Pure mechanical simulators and VR simulators are not ideal when addressing advanced endoscopic resection training, due to the inability to reproduce the elasticity, tissue properties and tactile feedback of human tissue [69]. Workshops with animal models are being organized in many specialized training centres with the potential to aid in speeding up the learning process and achieve initial competence in ESD in a safe learning environment with direct oneon-one expert supervision. This is especially relevant where there are few adequate cases in clinical practice, and expert supervision is not readily available or hard to organize [70-72]. Simulation with explanted animal organs like the oesophagus, stomach and colon, facilitates the execution of therapeutic endoscopic procedures in a more realistic fashion with lower costs compared to mechanical simulators [73]. Ex vivo models have the advantage of being easy to assemble, more affordable and raising less ethical issues when compared to live animal models. On the other hand, the ex vivo model lacks a certain degree of realism due to its inability to bleed, although modifications can permit simulated blood flow and bleeding [64,73-75]. Harvested organs can be attached to insertion tubes or assembled in plastic models, thus oesophageal, gastric and colonic models are available [76-79]. The Erlangen Active Simulator for Interventional Endoscopy (EASIE) was the pioneer and is the best known model, in which explanted organs are mounted in a human shaped plastic torso [80]. It has been suggested that ex vivo models cannot substitute in vivo training to acquire competence in ESD because even fresh cadaveric animal tissue is stiffer and generally more robust than live human tissue which alters the ESD technique. It is advised that learners proceed to live animal models soon after acquiring adequate basic ESD skills on explanted organs [72,74]. Animal models, generally anesthetized pigs, have breathing movements, heart beats, peristalsis, intraluminal secretions, tissue reaction to injection and electrocautery, and abdominal distension which more closely resembles the human setting. It is possible to deal with adverse events, such as bleeding and perforation in a more realistic setup. Usually, the submucosal injection is more difficult compared to human cases, with a lesser degree of bleeding, and often more fibrosis. The orientation of various organs can be different and pathological scenarios are generally difficult to be reproduced $[64,71,74,81]$. The thickness and stiffness of the gastric porcine 
mucosal layer appears to be different from the human stomach [82]. In fact, mucosal layer in this model is thinner in the proximal stomach and thicker in the distal area, particularly at the level of the greater curvature, where ESD is more challenging than in a similar human procedure. It has been suggested that the greater curvature, particularly the distal part of the porcine stomach is the least suitable place for ESD training [83]. Initial attempts ought to be in the gastric antrum and then progress can be made to more proximal regions of the stomach and other organs such as the oesophagus or colon $[70,76,78]$. Validity and clinical benefit of training ESD in this model and subsequent complication management has not been well established and is currently being investigated by our study group. Nevertheless, by training in the animal model it is possible to recognize a learning curve regarding procedure time, completeness of procedures and adverse events. A study demonstrated that the mean resection time was significantly decreased for porcine gastric ESDs in the second half of the study cases [71]. In another study, two novice endoscopists were able to decrease procedure times, perforation rate and achieve $100 \%$ en bloc resection after accomplishing 30 gastric ESDs in an ex vivo porcine model [77]. The rates of endoscopic closure for colorectal perforations by two non-experts increased from 40 to $60 \%$ in the first five cases compared to $100 \%$ in the last five procedures [75]. Lastly, four endoscopists without any ESD experience were able to perform uneventful human gastric ESD after training in ex and in vivo animal models, thereby demonstrating the transfer of skills to a patient-based setting [72]. Based on the few studies that are available on this subject, a minimum of 10-30 gastric ESD procedures in the animal model should be recommended before moving to human cases [77,84,85]. Performing ESD in the oesophagus is more demanding than gastric ESD. This is in part due to the thinner muscle layer and the tubular shape of the oesophagus which provides a limited space to work in [67]. It has been demonstrated that by training in ex vivo models for oesophageal ESD, endoscopists with experienced in gastric ESD, were able to reduce the operation time and the number of deep injuries to the muscularis propria after 10 procedures, when the five initial ESDs were compared to the final five [76]. Colorectal ESD is technically the most demanding. Difficult positioning and an increased risk for adverse events, mostly perforations, make it particularly challenging, even for the expert endoscopist. Training is therefore essential and animal models may play an essential role [74,86]. Live animal models for colorectal ESD are difficult to prepare as it requires adequate bowel preparation before attempting any procedure. For colorectal ESD training, porcine and bovine ex vivo models have demonstrated their feasibility $[75,79]$. In a study using an ex vivo model for colonic ESD, technical proficiency increased over 10 procedures. In the first two cases, incomplete resections and perforations occurred, whereas in the following cases procedure time decreased and no further adverse events occurred [78].

\section{A glance at the future}

Numerous simulators have been developed over the last decades. The aim of simulator-based training is to provide a platform for training in a specialized learning environment and the possibility to repeat procedures in order to gain competence before performing patient-based endoscopic procedures. Ideally, this reduces patient's burden and results in well-trained, well-prepared and to some extent competent endoscopists. Current simulators, whether (VR) simulators, ex vivo or in vivo models, are still lacking the degree of realism that would be necessary to achieve full competency at a level where certification could be applicable. The conclusion of a large overview of our current state is that simulators have proven their value in training novice endoscopists through their first steps in the world of flexible endoscopy. As well as at the far end of the spectrum, where they can be used to train a select group of experienced endoscopists in advanced endoscopic resection techniques. The large part in between seems to be void. The best example is the standard polypectomy training. A simulationbased scenario is not available for this kind of rather routine procedures, which however incur risks of adverse events and which is performed by virtually all endoscopists. Future research is needed to focus mainly on common therapeutic interventions such as polypectomy and EMR of sessile polyps up to $2 \mathrm{~cm}$, stricture dilatation, stent placement and bleeding scenarios like variceal bleeds using rubber band ligation or endoscopic therapy for ulcer bleeds. Studies should focus on validating and improving the performance of the models, but also on the transfer of skills to patient-based settings, a step that is often omitted but that is in fact the only proof of concurrent validity. Another vast area in the broad arsenal of GI endoscopists includes ERCP and endosonography. Endosonography is no longer a 
diagnostic procedure for the few where little harm is done but is widely practised with an increasing number of therapeutic possibilities. This makes EUS more complex. The therapeutic procedures have a particularly significant overlap with ERCP and demand a great deal of expertise. It seems that we have just touched the tip of the iceberg when it comes to simulation-based training for ERCP and EUS. This is in huge contrast with the fast developments in therapeutic indications and possibilities that these procedures offer. Models for ERCP training are already available but the full potential of these models have not yet been established, as well as their impact on clinical practice. Regarding EUS, data are even more scarce.

In a world where we are striving for more transparency in competency and procedural outcomes, simulation-based training is bound to have an increasingly important role. Certification and credentialing of simulator derived expertise would be the next logical step to ensure an optimal safety environment for everybody involved. The final stage of learning will always be to some extent patientbased. Our goal is that when this stage is reached we are dealing with trainees who have been well prepared by simulation-based scenarios.

\section{Practice points}

- The use of simulators in the early training setting accelerates the learning curve of basic endoscopy skills acquisition.

- Currently, both ex vivo and in vivo models provide the best platform to train advanced endoscopic procedures.

- There is no simulation-based training scenario available for common procedures like standard polypectomy.

\section{Research agenda}

- Development of a training platform for standard polypectomy and EMR of sessile polyps.

- Further development of simulation-based platforms for endosonography and ERCP and study of the transfer of simulator derived skills to patient-based endoscopy.

- Development of structured training programs with optimal use of simulator-based training.

\section{Conflict of interest}

None.

\section{References}

[1] Bini EJ, Firoozi B, Choung RJ, Ali EM, Osman M, Weinshel EH. Systematic evaluation of complications related to endoscopy in a training setting: a prospective 30-day outcomes study. Gastrointest Endosc 2003;57:8-16.

[2] Ekkelenkamp VE, Koch AD, de Man RA, Kuipers EJ. Training and competence assessment in GI endoscopy: a systematic review. Gut 2016;65(4):607-15.

[3] Carter FJ, Schijven MP, Aggarwal R, Grantcharov T, Francis NK, Hanna GB, et al. Consensus guidelines for validation of virtual reality surgical simulators. Surg Endosc 2005;19:1523-32.

[4] Gerson LB, Van Dam J. Technology review: the use of simulators for training in GI endoscopy. Gastrointest Endosc 2004; 60:992-1001.

[5] Carter FJ, Schijven MP, Aggarwal R, Grantcharov T, Francis NK, Hanna GB, et al. Consensus guidelines for validation of virtual reality surgical simulators. Simul Healthc 2006;1:171-9.

[6] Walsh CM, Sherlock ME, Ling SC, Carnahan H. Virtual reality simulation training for health professions trainees in gastrointestinal endoscopy. Cochrane Database Syst Rev 2012;6:CD008237. 
[7] Moorthy K, Munz Y, Jiwanji M, Bann S, Chang A, Darzi A. Validity and reliability of a virtual reality upper gastrointestinal simulator and cross validation using structured assessment of individual performance with video playback. Surg Endosc 2004; 18:328-33.

[8] Symbionix.

[9] Ruppin MCH. Practical training using a new gastrointestinal phantom. Endoscopy 1974;6:127-31.

[10] Hochberger J, Euler K, Naegel A, Hahn EG, Maiss J. The compact Erlangen active simulator for interventional endoscopy: a prospective comparison in structured team-training courses on 'endoscopic hemostasis' for doctors and nurses to the ‘endo-trainer’ model. Scand J Gastroenterol 2004;39:895-902.

[11] Giulio ED, Fregonese D, Casetti T, Cestari R, Chilovi F, D'Ambra G, et al. Training with a computer-based simulator achieves basic manual skills required for upper endoscopy: a randomized controlled trial. Gastrointest Endosc 2004;60:196-200.

[12] Ferlitsch A, Schoefl R, Puespoek A, Miehsler W, Schoeniger-Hekele M, Hofer H, et al. Effect of virtual endoscopy simulator training on performance of upper gastrointestinal endoscopy in patients: a randomized controlled trial. Endoscopy 2010; 42:1049-56.

[13] Ende A, Zopf Y, Konturek P, Naegel A, Hahn EG, Matthes K, et al. Strategies for training in diagnostic upper endoscopy: a prospective, randomized trial. Gastrointest Endosc 2012;75:254-60.

[14] Ferlitsch A, Glauninger P, Gupper A, Schillinger M, Haefner M, Gangl A, et al. Evaluation of a virtual endoscopy simulator for training in gastrointestinal endoscopy. Endoscopy 2002;34:698-702.

[15] Sarker SK, Albrani T, Zaman A, Kumar I. Procedural performance in gastrointestinal endoscopy: live and simulated. World J Surg 2010;34:1764-70.

[16] Kim S, Spencer G, Makar GA, Ahmad NA, Jaffe DL, Ginsberg GG, et al. Lack of a discriminatory function for endoscopy skills on a computer-based simulator. Surg Endosc Interv Tech 2010;24:3008-15.

[17] McConnell R, Kim S, Ahmad NA, Falk GW, Forde KA, Ginsberg GG, et al. Lack of discriminatory function for endoscopy skills on a computer-based simulator. Gastrointest Endosc 2011;73:AB432.

[18] Shirai Y, Yoshida T, Shiraishi R, Okamoto T, Nakamura H, Harada T, et al. Prospective randomized study on the use of a computer-based endoscopic simulator for training in esophagogastroduodenoscopy. J Gastroenterol Hepatol 2008;23: $1046-50$.

[19] Qiao W, Bai Y, Lv R, Zhang W, Chen Y, Lei S, et al. The effect of virtual endoscopy simulator training on novices: a systematic review. PLOS ONE 2014;9.

[20] Plooy AM, Hill A, Horswill MS, Cresp ASG, Watson MO, Ooi SY, et al. Construct validation of a physical model colonoscopy simulator. Gastrointest Endosc 2012;76:144-50.

[21] Sedlack RE, Baron TH, Downing SM, Schwartz AJ. Validation of a colonoscopy simulation model for skills assessment. Am J Gastroenterol 2007;102:64-74.

[22] Fayez R, Feldman LS, Kaneva P, Fried GM. Testing the construct validity of the Simbionix GI Mentor II virtual reality colonoscopy simulator metrics: module matters. Surg Endosc Interv Tech 2010;24:1060-5.

[23] Felsher JJ, Olesevich M, Farres H, Rosen M, Fanning A, Dunkin BJ, et al. Validation of a flexible endoscopy simulator. Am J Surg 2005;189:497-500.

[24] Grantcharov TP, Carstensen L, Schulze S. Objective assessment of gastrointestinal endoscopy skills using a virtual reality simulator. JSLS 2005;9:130-3.

[25] Koch AD, Buzink SN, Heemskerk J, Botden SMBI, Veenendaal R, Jakimowicz JJ, et al. Expert and construct validity of the Simbionix GI Mentor II endoscopy simulator for colonoscopy. Surg Endosc Interv Tech 2008;22:158-62.

[26] Ritter EM, McClusky IDA, Lederman AB, Gallagher AG, Smith CD. Objective psychomotor skills assessment of experienced and novice flexible endoscopists with a virtual reality simulator. J Gastrointest Surg 2003;7:871-8.

[27] Haycock AV, Bassett P, Bladen J, Thomas-Gibson S. Validation of the second-generation Olympus colonoscopy simulator for skills assessment. Endoscopy 2009;41:952-8.

[28] Koch AD, Haringsma J, Schoon EJ, de Man RA, Kuipers EJ. A second-generation virtual reality simulator for colonoscopy: validation and initial experience. Endoscopy 2008;40:735-8.

[29] Sugden C, Aggarwal R, Banerjee A, Haycock A, Thomas-Gibson S, Williams CB, et al. The development of a virtual reality training curriculum for colonoscopy. Ann Surg 2012;256:188-92.

[30] Datta V, Mandalia M, Mackay S, Darzi A. The PreOp flexible sigmoidoscopy trainer: validation and early evaluation of a virtual reality based system. Surg Endosc 2002;16:1459-63.

[31] MacDonald J, Ketchum J, Williams RG, Rogers LQ. A lay person vs a trained endoscopist: can the preop endoscopy simulator detect a difference? Surg Endosc Interv Tech 2003;17:896-8.

[32] Mahmood T, Darzi A. A study to validate the colonoscopy simulator: it is usefully discriminatory for more than one measurable outcome. Surg Endosc 2003;17:1583-9.

[33] Tuggy ML. Virtual reality flexible sigmoidoscopy simulator training: impact on resident performance. J Am Board Fam Pract 1998;11:426-33.

[34] Ahad S, Boehler M, Schwind CJ, Hassan I. The effect of model fidelity on colonoscopic skills acquisition. A randomized controlled study. J Surg Educ 2013;70:522-7.

[35] Ahlberg G, Hultcrantz R, Jaramillo E, Lindblom A, Arvidsson D. Virtual reality colonoscopy simulation: a compulsory practice for the future colonoscopist? Endoscopy 2005;37:1198-204.

[36] Kruglikova I, Grantcharov TP, Drewes AM, Funch-Jensen P. The impact of constructive feedback on training in gastrointestinal endoscopy using high-fidelity virtual-reality simulation: a randomised controlled trial. Gut 2010;59:181-5.

[37] Mahmood T, Darzi A. The learning curve for a colonoscopy simulator in the absence of any feedback: No feedback, no learning. Surg Endosc 2004;18:1224-30.

[38] Sedlack RE, Kolars JC, Alexander JA. Computer simulation training enhances patient comfort during endoscopy. Clin Gastroenterol Hepatol 2004;2:348-52.

[39] Snyder CW, Vandromme MJ, Tyra SL, Hawn MT. Retention of colonoscopy skills after virtual reality simulator training by independent and proctored methods. Am Surg 2010;76:743-6.

[40] Park J, MacRae H, Musselman LJ, Rossos P, Hamstra SJ, Wolman S, et al. Randomized controlled trial of virtual reality simulator training: transfer to live patients. Am J Surg 2007;194:205-11. 
[41] Van Sickle KR, Buck L, Willis R, Mangram A, Truitt MS, Shabahang M, et al. A multicenter, simulation-based skills training collaborative using shared GI mentor II systems: results from the Texas association of surgical skills laboratories (TASSL) flexible endoscopy curriculum. Surg Endosc Interv Tech 2011;25:2980-6.

[42] Haycock A, Koch AD, Familiari P, van Delft F, Dekker E, Petruzziello L, et al. Training and transfer of colonoscopy skills: a multinational, randomized, blinded, controlled trial of simulator versus bedside training. Gastrointest Endosc 2010;71: 298-307.

[43] G W. The world of civil simulators. Flight Int Mag 1978;435.

[44] Frimberger E, von Delius S, Rösch T, Karagianni A, Schmid RM, Prinz C. A novel and practicable ERCP training system with simulated fluoroscopy. Endoscopy 2008;40:517-20.

[45] Leung JW, Lee JG, Rojany M, Wilson R, Leung FW. Development of a novel ERCP mechanical simulator. Gastrointest Endosc 2007;65:1056-62.

[46] von Delius S, Thies P, Meining A, Wagenpfeil S, Burian M, Huber W, et al. Validation of the X-vision ERCP training system and technical challenges during early training of sphincterotomy. Clin Gastroenterol Hepatol 2009;7:389-96.

[47] Lim BS, Leung JW, Lee J, Yen D, Beckett L, Tancredi D, et al. Effect of ERCP mechanical simulator (EMS) practice on trainees ERCP performance in the early learning period: US multicenter randomized controlled trial. Am J Gastroenterol 2011;106: 300-6.

[48] Liao WC, Leung J, Wang HP, Chang WH, Chu CH, Lin JT, et al. Coached practice using ERCP mechanical simulator improves trainees' ERCP performance: a randomized controlled trial. Endoscopy 2013;45:799-805.

[49] Sedlack RE, Petersen BT, Kolars JC. The impact of a hands-on ERCP workshop on clinical practice. Gastrointest Endosc 2005;61:67-71.

[50] Parra-Blanco A, Gonzalez N, Gonzalez R, Ortiz-Fernandez-Sordo J, Ordieres C. Animal models for endoscopic training: do we really need them? Endoscopy 2013;45:478-84.

[51] Neumann M, Mayer G, Ell C, Felzmann T, Reingruber B, Horbach T, et al. The Erlangen endo-trainer: life-like simulation for diagnostic and interventional endoscopic retrograde cholangiography. Endoscopy 2000;32:906-10.

[52] Sedlack R, Petersen B, Binmoeller K, Kolars J. A direct comparison of ERCP teaching models. Gastrointest Endosc 2003;57: 886-90.

[53] Bittner IJG, Mellinger JD, Imam T, Schade RR, MacFadyen Jr BV. Face and construct validity of a computer-based virtual reality simulator for ERCP. Gastrointest Endosc 2010;71:357-64.

[54] Sahakian AB, Laine L, Jamidar PA, Siddiqui UD, Duffy A, Ciarleglio MM, et al. Can a computerized simulator assess skill level and improvement in performance of ERCP? Dig Dis Sci. 2016 Mar;61(3):722-30.

[55] Grimm H, Binmoeller KF, Soehendra N. Endosonography-guided drainage of a pancreatic pseudocyst. Gastrointest Endosc 1992;38:170-1.

[56] Barthet M, Gasmi M, Boustiere C, Giovannini M, Grimaud JC, Berdah S, et al. EUS training in a live pig model: does it improve echo endoscope hands-on and trainee competence? Endoscopy 2007;39:535-9.

[57] Haycock AV, Youd P, Bassett P, Saunders BP, Tekkis P, Thomas-Gibson S. Simulator training improves practical skills in therapeutic GI endoscopy: results from a randomized, blinded, controlled study. Gastrointest Endosc 2009;70:835-45. e2.

[58] Committee AT, Hwang JH, Konda V, Abu Dayyeh BK, Chauhan SS, Enestvedt BK, et al. Endoscopic mucosal resection. Gastrointest Endosc 2015;82:215-26.

[59] Terasaki M, Tanaka S, Oka S, Nakadoi K, Takata S, Kanao H, et al. Clinical outcomes of endoscopic submucosal dissection and endoscopic mucosal resection for laterally spreading tumors larger than $20 \mathrm{~mm}$. J Gastroenterol Hepatol 2012;27: 734-40.

[60] Toyokawa T, Inaba T, Omote S, Okamoto A, Miyasaka R, Watanabe K, et al. Risk factors for perforation and delayed bleeding associated with endoscopic submucosal dissection for early gastric neoplasms: analysis of 1123 lesions. J Gastroenterol Hepatol 2012;27:907-12.

[61] Probst A, Golger D, Anthuber M, Markl B, Messmann H. Endoscopic submucosal dissection in large sessile lesions of the rectosigmoid: learning curve in a European center. Endoscopy 2012;44:660-7.

[62] Oda I, Odagaki T, Suzuki H, Nonaka S, Yoshinaga S. Learning curve for endoscopic submucosal dissection of early gastric cancer based on trainee experience. Dig Endosc 2012;24(Suppl. 1):129-32.

[63] Chiu PW, Teoh AY, To KF, Wong SK, Liu SY, Lam CC, et al. Endoscopic submucosal dissection (ESD) compared with gastrectomy for treatment of early gastric neoplasia: a retrospective cohort study. Surg Endosc 2012;26:3584-91.

[64] Coman RM, Gotoda T, Draganov PV. Training in endoscopic submucosal dissection. World J Gastrointest Endosc 2013;5: 369-78.

[65] Farhat S, Chaussade S, Ponchon T, Coumaros D, Charachon A, Barrioz T, et al. Endoscopic submucosal dissection in a European setting. A multi-institutional report of a technique in development. Endoscopy 2011;43:664-70.

[66] Kakushima N, Fujishiro M, Kodashima S, Muraki Y, Tateishi A, Omata M. A learning curve for endoscopic submucosal dissection of gastric epithelial neoplasms. Endoscopy 2006;38:991-5.

[67] Oyama T, Yahagi N, Ponchon T, Kiesslich T, Berr F. How to establish endoscopic submucosal dissection in Western countries. World J Gastroenterol 2015;21:11209-20.

[68] Yamamoto S, Uedo N, Ishihara R, Kajimoto N, Ogiyama H, Fukushima Y, et al. Endoscopic submucosal dissection for early gastric cancer performed by supervised residents: assessment of feasibility and learning curve. Endoscopy 2009;41:923-8.

[69] Hochberger J, Maiss J, Magdeburg B, Cohen J, Hahn EG. Training simulators and education in gastrointestinal endoscopy: current status and perspectives in 2001. Endoscopy 2001;33:541-9.

[70] Berr F, Ponchon T, Neureiter D, Kiesslich T, Haringsma J, Kaehler GF, et al. Experimental endoscopic submucosal dissection training in a porcine model: learning experience of skilled Western endoscopists. Dig Endosc 2011;23:281-9.

[71] Parra-Blanco A, Arnau MR, Nicolas-Perez D, Gimeno-Garcia AZ, Gonzalez N, Diaz-Acosta JA, et al. Endoscopic submucosal dissection training with pig models in a Western country. World J Gastroenterol 2010;16:2895-900.

[72] Vazquez-Sequeiros E, de Miquel DB, Olcina JR, Martin JA, Garcia M, Lucas DJ, et al. Training model for teaching endoscopic submucosal dissection of gastric tumors. Rev Esp Enferm Dig 2009;101:546-52.

[73] Martinek J, Stefanova M, Suchanek S, Zavada F, Svobodova B, Strosova A, et al. Training of different endoscopic skills on exvivo animal model. Simul Healthc 2014;9:112-9. 
[74] Herreros de Tejada A. ESD training: a challenging path to excellence. World J Gastrointest Endosc 2014;6:112-20.

[75] Yoshida N, Yagi N, Inada Y, Kugai M, Kamada K, Katada K, et al. Possibility of ex vivo animal training model for colorectal endoscopic submucosal dissection. Int J Colorectal Dis 2013;28:49-56.

[76] Tanaka S, Morita Y, Fujita T, Wakahara C, Ikeda A, Toyonaga T, et al. Ex vivo pig training model for esophageal endoscopic submucosal dissection (ESD) for endoscopists with experience in gastric ESD. Surg Endosc 2012;26:1579-86.

[77] Kato M, Gromski M, Jung Y, Chuttani R, Matthes K. The learning curve for endoscopic submucosal dissection in an established experimental setting. Surg Endosc 2013;27:154-61.

[78] Hon SS, Ng SS, Lee JF, Li JC, Lo AW. In vitro porcine training model for colonic endoscopic submucosal dissection: an inexpensive and safe way to acquire a complex endoscopic technique. Surg Endosc 2010;24:2439-43.

[79] Pioche M, Rivory J, Aguero-Garcete G, Guillaud O, O'Brien M, Lafon C, et al. New isolated bovine colon model dedicated to colonic ESD hands-on training: development and first evaluation. Surg Endosc 2015;29:3209-15.

[80] Hochberger J, Neumann M, Hohenberger W, Hahn EG. Neuer Endoskopie-Trainer für die therapeutische flexible Endoskopie. Z Gastroenterol 1997;35:722-3.

[81] Bok GH, Cho JY. ESD hands-on course using ex vivo and in vivo models in South Korea. Clin Endosc 2012;45:358-61.

[82] Shi Q, Zhong YS, Yao LQ, Zhou PH, Xu MD, Wang P. Endoscopic submucosal dissection for treatment of esophageal submucosal tumors originating from the muscularis propria layer. Gastrointest Endosc 2011;74:1194-200.

[83] Horii J, Goto O, Shimoda M, Sasaki M, Fujimoto A, Ochiai Y, et al. Which part of a porcine stomach is suitable as an animal training model for gastric endoscopic submucosal dissection? Endoscopy 2016;48:188-93.

[84] Coda S, Trentino P, Antonellis F, Porowska B, Gossetti F, Ruberto F, et al. A western single-center experience with endoscopic submucosal dissection for early gastrointestinal cancers. Gastric Cancer 2010;13:258-63.

[85] Deprez PH, Bergman JJ, Meisner S, Ponchon T, Repici A, Dinis-Ribeiro M, et al. Current practice with endoscopic submucosal dissection in Europe: position statement from a panel of experts. Endoscopy 2010;42:853-8.

[86] Uraoka T, Parra-Blanco A, Yahagi N. Colorectal endoscopic submucosal dissection: is it suitable in western countries? J Gastroenterol Hepatol 2013;28:406-14. 